\title{
CINEMA E PSICANÁLISE: CONSIDERAÇÕES SOBRE O TEMPO E A
} MEMÓRIA

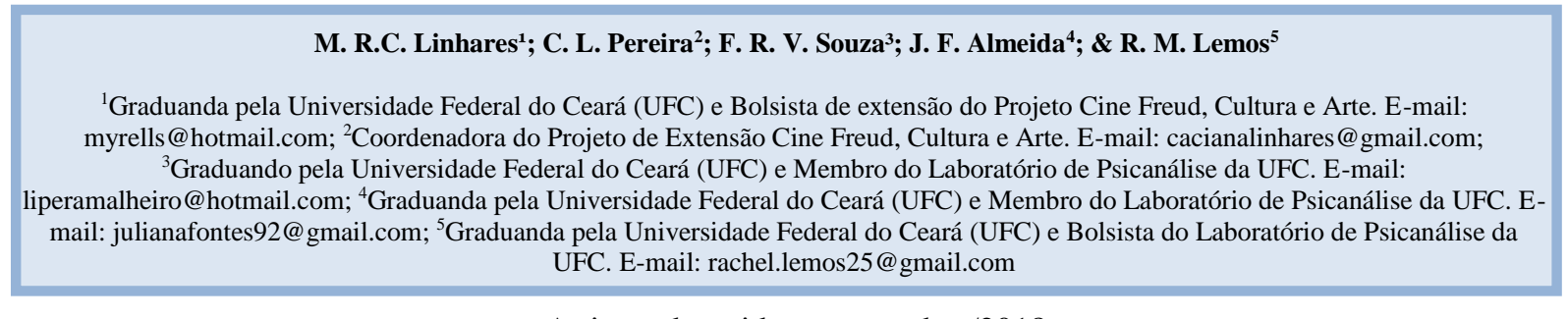

Artigo submetido em setembro/2018

\section{RESUMO}

$\mathrm{O}$ artigo investiga a relação entre os mecanismos presentes na montagem e os mecanismos em jogo na técnica da associação livre, com vistas a contribuir para o debate mais geral que, no contexto das relações entre Cinema e Psicanálise, se voltam para o estatuto do tempo. Quanto à perspectiva do Cinema, trabalhamos com Andrei Tarkovski, privilegiando suas formulações sobre o tempo. Para o diretor, respeitar o tempo que está impresso materialmente em cada tomada é compromisso ético do artista com o seu material de trabalho. Quanto à Psicanálise, nos reportamos à problemática do tempo em sua relação com a técnica da associação livre e a noção de interpretação. A partir da experiência no Projeto Cine Freud, Cultura e Arte e da execução de um grupo de trabalho realizado no âmbito do Laboratório de Psicanálise da UFC, o artigo apresenta uma pesquisa de cunho bibliográfico

PALAVRAS-CHAVE: Associação Livre. Montagem. Cinema. Psicanálise. Tempo.

\section{CINEMA AND PSYCHOANALYSIS: CONSIDERATIONS ABOUT TIME AND MEMORY}

\begin{abstract}
This work investigates the relationship between the mechanisms present in the montage and the mechanisms at play in the technique of free association, with views to contribute to a more general debate that, in the context of the relations between Cinema and Psychoanalysis, turn to the statute of time. Regarding the cinema's perspective, we worked with Andrei Tarkovski, focusing on his formulations about time. For the director, respecting the time that is printed
\end{abstract}

materially in each shot is the artist's ethical commitment to his material. As for Psychoanalysis, we refer to the problematic of time in its relation to the technique of free association and the notion of interpretation. From the experience of the Projeto Cine Freud, Cultura e Arte and the execution of a work group carried out within the scope of the Laboratório de Psicanálise da UFC, the work presents a bibliographical research.

KEYWORDS: Free Association. Montage. Cinema. Psychoanalysis. Time.

\section{INTRODUÇÃO}

O Cine Freud, Cultura e Arte, projeto de extensão vinculado ao Laboratório de Psicanálise da UFC, que visa promover a interlocução entre Arte, Psicanálise e o campo dos Estudos Culturais, articula a análise dos fenômenos culturais aos processos de subjetivação. Propõe-se a construção de dispositivos de formação discente que permitam problematizar os 
fenômenos subjetivos implicados na experiência contemporânea, considerando a diversidade cultural como constitutiva desta experiência.

A partir do contato direto com essas áreas, possibilitado pelo Projeto e por um grupo de trabalho que se deu no semestre 2018.1, tivemos a possibilidade de nos aproximar das teorias do Cinema em sua interlocução com a Psicanálise. Neste artigo pretendemos tratar, em especial, sobre como a técnica do Cinema pode ser utilizada para apreender a técnica da Psicanálise e assim discutir sobre temáticas que por ambas são abordadas, para, com isso, contribuir com o estudo da Psicanálise por meio da Arte.

O artigo investigará a relação entre os mecanismos presentes na montagem e os mecanismos em jogo na técnica da associação livre, com vistas a contribuir para o debate mais geral que, no contexto das relações entre Cinema e Psicanálise, se voltam para a memória e para o tempo. Para isto nos propomos a investigar qual a relação entre tempo e interpretação na Psicanálise; pesquisar qual o efeito que a interpretação ocasiona na cadeia associativa; estudar a concepção de tempo e memória em Tarkovski e, considerando a posição de Tarkovski frente ao material fílmico, extrairemos elementos que lancem luz sobre o procedimento da interpretação psicanalítica.

Quanto à perspectiva do Cinema, utilizaremos a concepção técnica e teórica de Andrei Tarkovski, privilegiando suas formulações sobre o tempo. Para o diretor, respeitar o tempo que está impresso materialmente em cada tomada é compromisso ético do artista com o seu material de trabalho. Quanto à Psicanálise, nos reportaremos à problemática do tempo em sua relação com a técnica da associação livre e a noção de interpretação. O recorte temático incidirá sobre as categorias de tempo, montagem, associação livre e interpretação. Recorte que deverá contribuir para a interlocução entre Cinema e Psicanálise por abrir chaves de leitura relativas aos estudos que abarcam a problemática do tempo e da memória.

\section{ASSOCIAÇÃO LIVRE E MONTAGEM}

\subsection{A TÉCNICA DA ASSOCIAÇÃO LIVRE}

As associações se assemelham a pensamentos involuntários, que geralmente são considerados como um estorvo, e que com frequência irrompem a continuidade da narração. Ao solicitar ao analisando que este se deixe levar pelo fluxo contínuo de pensamentos, imagens 
ou emoções - relatando-os sem omitir nenhuma ideia ou sensação, ainda que sejam vergonhosos, penosos ou pareçam irrelevantes - Freud começa a definir com precisão o que constituirá a regra fundamental da análise. Freud afirma que os esquecimentos e interrupções que surgem no discurso ocorrem em decorrência de forças psíquicas que favorecem a resistência à recuperação das memórias patogênicas (FREUD, 1905/1996). Essa noção de um núcleo patogênico da memória era correlativa à concepção de trauma que marcou o advento da psicanálise. Com a demarcação cada vez maior de seu objeto - o inconsciente - e a respectiva complexificação de suas noções, a noção de trauma passou a assumir um lugar-chave na subversão operada por Freud em torno da noção de tempo. Uma das consequências dessas transformações foi a interrogação em torno da noção realidade e de um núcleo patológico da memória, o que levou Freud a construções importantes como a de realidade psíquica e de fantasia, que romperam a fronteira entre normal e patológico. "Como sublinhou Paola Mieli, a noção de trauma implica a elaboração de um conceito particular de tempo psíquico, em que 'o trauma se constitui em uma escansão temporal que ocorre só-depois" (JORGE, 2017, p.41).

É também nesse texto que Freud afirma que a terapia analítica não tem como objetivo acrescentar ou introduzir nada de novo, apontando que a técnica psicanalítica tem como base a concepção de que as representações inconscientes são a causa imediata dos sintomas patológicos e que trazer à tona o conteúdo inconsciente acontece sob uma resistência contínua do analisando, pois esse desvelamento do inconsciente está vinculado ao desprazer, fazendo com que o analisando o rejeite vez após outra.

O analisando deve comunicar os diversos pensamentos que, em uma conversa normal, gostaria de pôr de lado devido a certas críticas e objeções, mas que no momento da análise, apesar dos pensamentos parecerem absurdos ou irrelevantes, o analisando deve dizê-los. Assim, age como se fosse um viajante sentado à janela de um trem que descreve a alguém que se encontra mais adentro, as vistas que têm do lado de fora (FREUD, 1913/2010). O discurso orientado pela regra da associação livre não vai em qualquer direção: paradoxalmente, não é livre, mas progride em direção a um núcleo que Freud irá ordenar sob a categoria de fantasia. A intervenção do analista jamais deve ser sugestiva ou imperativa, mas sim equívoca, pois a pluralidade de sentido dá suporte à passagem das formações inconscientes no discurso (JORGE, 2017).

Com o advento da técnica da associação livre, que significou o abandono da hipnose, o papel do analista deixou de ser a tentativa de colocar em foco um momento ou problema 
específico e passou a ser observar tudo o que está no presente momento, na superfície da fala do ponto de vista da técnica, essa posição de escuta é denominada atenção flutuante. Assim, surge um novo tipo de divisão de trabalho, um em que o analista revela essas resistências desconhecidas e, estando estas vencidas, o paciente relaciona às situações e vinculações esquecidas sem qualquer dificuldade. O objetivo é, então, preencher lacunas na memória e superar resistências devidas ao recalque. Abrimos aqui um parêntese para uma observação: essa revelação das resistências por parte do analista vai sofrer um processo de redução importante, pois o inconsciente está na superfície da fala, e não num espaço separado desta. Esse movimento de redução, podemos já observar, vai contra a noção de uma substância inconsciente além ou atrás da fala - daí Lacan poder situar a interpretação do lado do corte.

Prosseguindo, a noção de recalque - operação que funda a divisão constitutiva do aparelho psíquico - leva Freud a afirmar que "o esquecimento de impressões, cenas, vivências reduz-se em geral a um bloqueio delas." (FREUD, 1914/2010, p. 148). Quando o paciente fala de algo que esqueceu, muitas vezes também afirma que sempre o soube, mas nunca pensou nisso. Ele também afirma que a amnésia infantil - tão importante para a teoria psicanalítica - é completamente contrabalanceada pelas lembranças encobridoras, que a totalidade do que é essencial na infância foi retido nessas lembranças. A questão é, então, saber como extrair os conteúdos inconscientes pela análise. Elas representam os anos esquecidos da infância. (FREUD, 1914/2010) É importante indicar que a infância, ainda que esteja referida às experiências vividas em determinado momento cronológico, implica uma articulação mais densa - central para a psicanálise - em torno da noção de tempo, pois passado, presente e futuro são construções do processo secundário (regidas pelo sistema consciente). O processo primário (que rege o sistema inconsciente) vai operar de modo a introduzir outro regime em nossa relação com o tempo. A articulação entre mito, história e linguagem são decisivos para o tratamento que Freud confere à infância, de modo que esta passa a constituir um espaço e um tempo de engendramento da linguagem e uma zona de fronteira entre os processos que regem o psiquismo.

\subsubsection{A INTERPRETAÇÃO DO ANALISTA}

O trabalho de análise consiste em duas partes diferentes - analista e analisando - ao qual a cada um é atribuído uma tarefa distinta. Ao analisando é atribuída a regra fundamental 
da psicanálise, a associação livre. A tarefa do analista consiste, então, em completar "aquilo que foi esquecido a partir dos traços que deixou atrás de si ou, mais corretamente, construí-lo”. Ele compara o trabalho do analista ao do arqueólogo ao afirmar que é um trabalho de escavação. No caso do arqueólogo, a escavação de algum local que foi destruído e soterrado ou algum prédio antigo, já o trabalho do analista diferencia-se por aquilo do qual está tratando não ser algo destruído, mas sim ainda vivo. (FREUD, 1937/1996)

$\mathrm{O}$ analista trabalha com as repetições de reações que têm como origem a infância e tudo o que acontece na transferência em conexão com essas repetições. Freud dá especial atenção ao funcionamento da memória, principalmente no que diz respeito às memórias infantis na constituição do trauma. Ele aponta que, por vezes, a memória retém um acontecimento considerado irrelevante em detrimento de um acontecimento mais importante, nomeando esse mecanismo de lembrança encobridora, que é uma espécie de imagem que busca cobrir e preservar um evento traumático para o sujeito, selecionando e combinando imagens consideradas triviais. (FREUD, 1899/1996)

Sobre o funcionamento do processo, verifica-se que "há duas forças psíquicas envolvidas na promoção desse tipo de lembranças. Uma dessas forças encara a importância da experiência como um motivo para procurar lembrá-la, enquanto a outra - uma resistência tenta impedir que se manifeste qualquer preferência dessa ordem.” (FREUD, 1899/1996, p. 290). Nesse sentido, a partir desses mecanismos, Freud postula que o que é registrado na memória da pessoa não é o acontecimento em si, prevalecendo a resistência, mas algo que, psiquicamente falando, está ligado a este acontecimento, prevalecendo o primeiro mecanismo. (FREUD, 1899/1996) Todo esse processo explicitado, que resulta na lembrança encobridora, retorna em sintomas, que causam algum tipo de sofrimento à pessoa, mas que também são a cicatriz, digamos, de sua divisão decorrente da entrada na linguagem. O sintoma traz sofrimento, mas, no limite de sua função, comporta um núcleo indestrutível. Assim, durante a análise, o papel do analista é chegar o mais próximo possível deste núcleo, a partir do que o analisando traz em sua fala em "livre" fluxo. A lembrança encobridora é uma espécie de pista deste trauma, que nunca poderá ser descoberto integralmente, apenas suas reminiscências, seus "restos". Trauma que já não é "patológico" no sentido de oposto à normal, mas que desvela o pathos da própria estrutura da fala e do psiquismo.

Assim, o trabalho de construção e interpretação do analista é apenas um trabalho preliminar. Ele completa um fragmento da construção e o comunica ao analisando de forma 
que o mesmo possa agir sobre ele. A partir desse novo material que surge, constrói-se então outro fragmento. Freud afirma que nos textos sobre a técnica, muito se fala acerca da interpretação e em seus efeitos, mas que ele considera o termo construção mais apropriado, pois a interpretação se refere a um elemento isolado do material enquanto uma construção é quando "se põe perante o sujeito da análise um fragmento de sua história primitiva, que ele esqueceu" (FREUD, 1937/1996, p. 279) de forma que há uma associação a outros aspectos da história do sujeito. (FREUD, 1937/1996).

Há críticas à Psicanálise que afirmam que a mesma funciona de forma que o analista “deteria o saber acerca do sujeito em análise” (BARBOSA, 2006, p. 32) e que as construções e interpretações estariam para além do conhecimento do analisando. Respondendo a essas críticas já em seu tempo, Freud determinou que os critérios dessa técnica são operacionais e que a construção não é o trabalho final de uma análise, pelo contrário, é um trabalho preliminar que "busca dissolver resistências e manter as associações do paciente em fluxo" (BARBOSA, 2006, p. 32). Quando o trabalho do analista é feito corretamente, ele mantém a cadeia associativa em movimento, independente da aceitação ou negativa do analisando ao que lhe foi apresentado. Assim, o trabalho psicanalítico funciona de tal forma que não há como objetivo um final alcançável no qual toda a história primitiva inconsciente do analisando esteja organizada e sob seu conhecimento, sendo um trabalho que se refaz a cada sessão. (BARBOSA, 2006). O final desse trabalho, que foge ao escopo deste trabalho, pode ser pensado a partir de determinados efeitos, e não pela apreensão do percurso realizado numa narrativa que privilegia determinada rede de sentido. Esta é uma das chaves interessantes para se pensar a interlocução entre Cinema e Psicanálise, pois o problema da forma vai exigir, em ambos os campos, um salto em direção a concepções da linguagem que considerem efeitos de sentido para além de concepções que só considerem face comunicativa da linguagem.

A noção de cadeia significante é crucial por ilustrar como as leis de produção do sentido devem ser consideradas no exercício da interpretação: o interesse envolvido na interpretação é o de indicar na sincronia, as diacronias das repetições inconscientes. A interpretação, servindo-se dos significantes postos em cena pelo analisando, o ato do analista insere um elemento que aponte para o sem sentido. Nesta operação está implicada a verdade do sujeito, na medida que esta diz da forma como ele se deparou com a pura diferença, com o impossível de atribuir sentido ao sem sentido originário. (FONTENELE, 2002)

Em consonância com esta formulação, o termo construção escolhido por Freud deixa 
claro que não há algo por trás do sujeito que virá à luz ao fim da análise, pois "não se trata de descascar as camadas da psique, como uma cebola, até encontrar o sujeito, escondido por trás dos símbolos a serem interpretados”. (BARBOSA, 2006, p. 33-34). O trabalho de interpretação do analista não está à serviço de revelar as profundezas psicológicas do paciente, mas sim que o própria fala desvela e emaranha. “(...) O que ela faz é construir uma escrita do desejo na qual o sujeito possa eventualmente se reconhecer, no fluir do discurso que o faz." (BARBOSA, 2006, p. 34).

\subsection{A MONTAGEM}

A montagem se transformou com a evolução do próprio cinema. Buscando resolver aquilo que sua própria técnica lhe apresentava como dificuldade, sua busca implica, a um só tempo, uma interrogação constante sobre os modos como um filme afeta e pode afetar o público. Como traz Froemming, "a ordem, a duração das tomadas das cenas, a justaposição, os momentos em que o corte deve incidir ou não, são decisões que um montador experiente tende a tomar tendo em vista os efeitos que pretende produzir no espectador" (FROEMMING, 2002, p. 27).

Ao tentar fazer um panorama sobre a relação do Cinema com a Psicanálise, a autora nos traz um breve histórico de como a montagem teria surgido como técnica dentro do Cinema. Ela aponta que um dos primeiros vestígios do que se tornaria a montagem no Cinema apareceu com D. W. Griffith, que tentava solucionar o problema da aparente não-linearidade dos filmes por meio da sincronia entre imagem, sons e palavras: "tornar linear o vínculo entre os planos, dando início a uma nova linguagem, uma espécie de sintaxe de imagens" (FROEMMING, 2002, p. 26).

A montagem evolui com a evolução do próprio Cinema, passando ela a buscar não mais resolver aquilo que sua própria técnica lhe apresentava como dificuldade, mas também a olhar o sujeito a qual o filme diz respeito, quem o assiste. A montagem vai, então, buscar entender como o filme afeta e pode afetar o público: “A ordem, a duração das tomadas das cenas, a justaposição, os momento sem que o corte deve incidir ou não, são decisões que um montador experiente tende a tomar tendo em vista os efeitos que pretende produzir no espectador." (FROEMMING, 2002, p. 27).

Um dos importantes teóricos e diretores de cinema, que ficou conhecido como o pai 
da montagem, Sergei Eisenstein, foi um dos pioneiros na sistematização da teoria e da técnica da montagem em cinema. Para ele, os efeitos sobre o espectador devem ser o que o diretor deve considerar na hora de compor um fato por meio do cinema e "cada área, cada parte, como luz, música, ritmo é convocado a participar no trabalho de composição de forma articulada, contribuindo para ilustrar o que é pretendido pelo diretor.” (FROEMMING, 2002, p. 30).

O corte e a montagem irão, portanto, desencadear profundas transformações nas noções de tempo e realidade no século XX. Nesse contexto podemos observar a posição de Tarkovski. Podemos ler de sua posição de que a montagem não é o centro da operação cinematográfica não no sentido de desmerecê-la ou desconsiderá-la na constituição do cinema, mas sua posição toma a montagem como que "ao avesso", numa operação negativa: a montagem, por recortar o tempo, desvela esse estranho efeito de continuidade do tempo. Vejamos mais detidamente esta proposição.

\title{
2.2.1 ANDREI TARKOVSKI E A MONTAGEM
}

Andrei Tarkovski, cineasta cujas contribuições foram e são importantes na história e desenvolvimento do Cinema, possui um contraponto muito interessante no que diz respeito à concepção de montagem que outros teóricos expõem. Para o diretor,

\begin{abstract}
A montagem não pode determinar o ritmo (nesse aspecto, ela só pode ser uma característica do estilo); na verdade, o fluxo do tempo num filme dá-se muito mais apesar da montagem do que por causa dela. O fluxo do tempo, registrado no fotograma, é o que o diretor precisa captar nas peças que tem diante de si na moviola. (TARKOVSKI, 2010, p. 139).
\end{abstract}

Nesse sentido, Tarkovski apresenta uma tese que parece inverter o vetor de nossa apreensão, quando diz que a montagem não é o fundamental para a concepção de um filme, mas sim o tempo que emerge das cenas filmadas. O diretor critica, inclusive, os defensores do que ele chama da ideia de cinema montagem: Essa ideia que "a montagem combina dois conceitos e gera um terceiro - parece-me, mais uma vez, incompatível com a natureza do cinema. A interação de conceitos jamais poderá ser o objetivo fundamental da arte." (TARKOVSKI, 2010, p. 135-136). Ao dizer isso, o diretor vai de encontro à ideia da montagem que combina fragmentos em busca de dar o ritmo do filme em si. Para ele "Montar um filme corretamente, com competência, significa permitir que as cenas e tomadas se juntem espontaneamente, uma vez que, em certo sentido, elas se montam por si mesmas, combinandose segundo o seu próprio padrão intrínseco, durante o processo de juntar e cortar." 
(TARKOVSKI, 2010, p. 136).

Assim, é necessário um olhar sensível do diretor para perceber o padrão e permitir que o filme se monte por si mesmo. Esse padrão, segundo ele, é percebido através de uma pressão que o tempo imprime sobre os quadros filmados, que flui através deles. Através dessa percepção temporal, que vai apontar o ritmo do filme, Tarkovski afirma, ainda, que "o diretor revela sua individualidade sobretudo através do ritmo, da sua percepção do tempo. O ritmo dá a cor a uma obra, imprimindo-lhe marcas estilísticas. Ele não é inventado, nem composto em bases arbitrárias e teóricas, mas nasce espontaneamente num filme, em resposta à consciência inata da vida que tem o diretor, à sua 'procura do tempo'.” (TARKOVSKI, 2010, p. 143).

A marca de um diretor, portanto, se dá não pela montagem, mas pela possibilidade de brincar com o tempo, criando uma maneira de modificá-lo, de esculpi-lo. “A distorção do tempo pode ser uma maneira de lhe dar expressão rítmica" (TARKOVSKI, 2010, p. 144). É a partir dessa habilidade de distorcer o tempo que o diretor, segundo Tarkovski, poderá possibilitar que o filme se monte, deixando sua marca e, de maneira concomitante, deixar o filme criar o seu ritmo e aparecer na tela.

\section{MATERIAIS E MÉTODOS}

A partir da experiência no Projeto Cine Freud, Cultura e Arte e a execução de um grupo de trabalho denominado "Cinema e Psicanálise" com os integrantes do Projeto no semestre 2018.1, realizamos um estudo bibliográfico que contemplou as aproximações entre os dois campos, tendo como recorte os conceitos implicados na técnica da associação livre - regra fundamental da Psicanálise - bem como os conceitos implicados na técnica da montagem (nesse contexto, certamente, temos diferentes perspectivas de autores e diretores do Cinema).

Para a articulação desses campos, nos embasamos nas obras Sobre a Psicanálise; Nota sobre o "Bloco Mágico"; Repetir, recordar e elaborar; Lembranças encobridoras; Construções em análise, de Sigmund Freud, e Esculpir o tempo, de Andrei Tarkovski. Além disso, utilizamos outros autores, a serem indicados nas referências, que deram suporte à pesquisa empreendida. 


\section{RESULTADOS E DISCUSSÕES}

A psicanálise, ao formalizar o inconsciente como um aparelho óptico, irá recolocar o uso do termo inconsciente, até então tomado como adjetivo de determinados eventos. A história da psicanálise é, desta forma, a história da formalização do inconsciente como um sistema regido por leis - leis ordenadas de tal modo que Lacan dirá, adiante, que o inconsciente se encontra "estruturado como linguagem". Deste modo, de concepções que situavam o inconsciente como o reino da irracionalidade (numa concepção onde tudo o que não é consciente é desprovido de leis), surge uma concepção que formula leis e procedimentos diferentes dos procedimentos conscientes. Nesse contexto, destacaremos uma primeira proposição: os processos inconscientes são intemporais. A noção de tempo é própria do trabalho do sistema consciente (Cs) por efeito do mecanismo de censura entre o sistema inconsciente (Ics) e o sistema Pcs/Cs que adequa o conteúdo de cada instância às exigências peculiares de cada uma. É característico do sistema Ics: a) a ausência de negação ou dúvida; b) os investimentos das representações sofrem processos de condensações e deslocamentos; c) os processos inconscientes são regidos pelo princípio do prazer e relacionam-se mais com a realidade psíquica que com a realidade externa. (JORGE, 2000).

A comparação que Freud faz acerca do trabalho do analista e do trabalho do arqueólogo traz a questão do tempo no trabalho da análise. Ele destaca que o tempo em que a análise vai operar "é a ausência mesma de temporalidade linear, é a temporalidade do inconsciente em que os três tempos - passado, presente e futuro - se misturam e o presente não substitui plenamente o passado.” (BARBOSA, 2006, p. 33). É na construção que se cria, então, o tempo da narrativa do sujeito (BARBOSA, 2006).

O compromisso do trabalho de interpretação do analista é com os significantes dispostos na cadeia associativa do analisando, de acordo com o principal objetivo analítico: levar o sujeito ao encontro de seu desejo. O efeito da interpretação condiz com a sua capacidade de dar destaque às relações do sujeito com seus significantes e o lugar que o sujeito concede a eles na sua fantasia. Fica patente que a interpretação deve operar com os elementos da realidade psíquica, sendo inútil e danoso ao tratamento que o analista se guie por uma realidade externa (FONTENELE, 2002).

O sofrimento neurótico decorre do conflito entre desejo e lei simbólica, e é a tentativa do sujeito de escapar das interdições da lei simbólica que dará uma forma singular ao seu dizer. 
A fantasia é cifrada por uma lógica inconsciente, ao modo de um sonho. A interpretação, portanto, deve propiciar a emergência de recortes da cena fantasística, para fazer emergir o sujeito em sua secção, ato que provocará mudanças na relação do sujeito com seu sofrimento. Este é o cerne do trabalho que cabe ao analista e ao analisando, e que, no decorrer da análise, levará o analista a trabalhar a sua saída, ou seja, será necessário que ele abandone a posição de suporte da fantasia do analisando. Atentamos para o fato que este trabalho em nada diz respeito à subjetividade do analista: não pode haver um excesso interpretativo, um simbolismo por parte deste, pois isto seria sugestão e caso isto ocorresse seria rompido o objetivo da análise. Seria perdido o descentramento associativo do sujeito enquanto o Eu seria fortalecido, impedindo que a travessia da fantasia acontecesse (FONTENELE, 2002).

A transferência, assim, é condição da interpretação e delimita o tempo e a incidência de sua efetuação. Neste ponto, temos o inconsciente estruturado como linguagem como norteador, para que o analista atente para as leis que regem o inconsciente. É o exame minucioso dessas leis que diz da pertinência de uma interpretação, que só tem seus efeitos na medida em que está referida às determinações inconscientes. A dialética temporal da interpretação deve tangenciar a eternidade do desejo e o tempo presente em sua ação. Pelas escansões que realiza no discurso do sujeito, o analista está aquém do sentido. O que produz a eficácia da interpretação é a articulação dos significantes - sem sentido - que estão aprisionados ao sintoma. Se tomarmos a citação da fala do analisando como enigma, garantimos um enigma na medida em que comparece a polissemia do dito que é deixado em aberto. (FONTENELE, 2002).

Selecionar e combinar os segmentos de fatos em cadeia, de modo a escutar, ver e reconhecer o que se encontra nestes segmentos e no tipo de ligação que os mantêm encadeados é o trabalho do cineasta, no qual percebemos uma analogia com o trabalho do analista. No Cinema, o tempo se presentifica de formas diferentes: na forma de um evento real, numa inscrição de fatos, em sua reconstrução, na recriação da vida. O brilho que o tempo dá ao filme diz da lógica do movimento das personagens, da posição dos objetos, sendo soberano a estes pois se refere ao sentimento e energia que se apresentam nas tomadas. O cinema opera com qualquer evento que se estenda no tempo (TARKOVSKI, 2010). Tarkovski se inspira no haicai que considera ser a observação da vida pura, delicada e sutil. Ele cita os seguintes haicais em seu livro Esculpir o Tempo (2010, p.76): 
A lua brilha fria;

Perto do velho mosteiro

Um lobo uiva.
Silêncio no campo.

Uma borboleta voava;

Depois adormeceu.
Enquanto passa

A lua cheia mal toca

Os anzóis entre as ondas

O diretor indica, ainda, que o haicai parece muito próximo à verdade do cinema, pois, para ele, a imagem só pode ser concretizada a partir de formas naturais e reais. É crucial que a imagem seja específica, é isso que a torna única (TARKOVSKI, 2010). Para ele, a pureza do cinema "não se revela na adequação simbólica das imagens, mas na capacidade dessas imagens expressarem um fato específico único e verdadeiro.” (TARKOVSKI, 2010, p.83).

Partindo da constatação de que a obra de arte é um testemunho do inconsciente, nos debruçamos sobre o livro "Esculpir o tempo", com o intuito de ter acesso a um saber do inconsciente que a obra carrega. Nos interessou, particularmente, a concepção de verdade enquanto a singularidade de uma experiência que sustenta o trabalho do diretor de esculpir o tempo, retirando excessos da filmagem original para respeitar a lógica inerente a cada fotograma. No dispositivo analítico, o analista, na posição de objeto, convoca um sujeito particular a criar um saber sobre sua verdade. Este saber é integralmente singular e interpretado tanto pelo analista quanto pelo analisando. A interpretação em psicanálise é de caráter inacabado, sendo impossível reconstituir o sentido original, barrado ao sujeito. Freud identifica, então, uma dissimetria característica da linguagem: esta se presentifica no irredutível do conflito psíquico, que comporta uma lógica própria do processo de tradução do sistema Ics para o sistema Cs. Esta lógica, intrínseca à fala associativa do analisando, é o material com que o analista trabalha ao interpretar. Essa tarefa deve comportar a polissemia, respeitando as leis que regem a associação livre. A interpretação é um trabalho de desmontagem dos procedimentos operados pela censura. $\mathrm{O}$ trabalho interpretativo só tem compromisso ético com o objetivo do tratamento psicanalítico, na medida em que possibilita o recorte das cenas fantasísticas para fazer emergir o sujeito em sua divisão, via pela qual o analisando poderá vencer seu sofrimento (FONTENELE, 2002).

Para Tarkovski (2010), o filme retira o homem do encantamento do silêncio, possibilita que ele liberte o espírito das angústias e coisas vãs que o oprimem. $\mathrm{O}$ diretor revela que seu mais ardente desejo sempre foi o de conseguir se expressar com absoluta sinceridade. Diferenciando-se de outras cineastas que buscam conduzir o espectador a partir de um simbolismo, Tarkovski nunca tem como objetivo impor aos espectadores, sua visão de mundo, postura ética cara à psicanálise, a de que o analista se abstenha de impor sua visão de mundo 
particular.

É o funcionamento descontínuo do sistema percepção-consciência (Pcp-Cs) que está na origem da ideia de tempo (FREUD, 1925/2011). O tempo é condição da existência de um 'Eu', no entanto, não se trata de uma temporalidade linear e cronológica, mas um tempo particular que vincula o homem à sua memória (TARKOVSKI, 2010). Na psicanálise, temos que este tempo não se refere a uma essência da natureza perceptiva do homem, mas, pelo contrário, este tempo, ligado a traços mnêmicos, é fabricado, é artifício construído a partir de uma lógica que tem como analogia o bloco mágico: "Nós teríamos um sistema Pcp-Cs que acolhe as percepções, mas não conserva traço duradouro delas" (FREUD, 1925/2011, p.269). O investimento no aparelho psíquico se dá pela via pulsional. Este investimento é pulsátil, marcado por interrupções, e é essa descontinuidade que nos oferece a origem do conceito de tempo (RIVERA, 2008). Freud supõe que inervações de investimento são enviadas e novamente recolhidas, de modo que os traços duradouros que chegam da percepção são construídos em sistema mnemônicos inconscientes. Assim que o investimento é interrompido apaga-se a consciência e cessa a operação do sistema. Esta é uma ilustração, um modelo do cintilar e esvanecer da consciência na percepção, que compõe a ampla noção de tempo na lógica do trauma e da memória (FREUD, 1925/2011). Rivera, a partir de sua leitura do Bloco Mágico, indica a "memória como montagem, jogo entre o que se vê e o que fica invisível, apesar de inscrito. Mas também indica a presença inquietante do que fica fora de inscrição.” (RIVERA, 2008, p.60).

Em psicanálise, o tempo do desejo é o presente e as formações inconscientes que emergem da cadeia associativa estão próximas da lógica do tempo pulsional, que apresentamos brevemente acima. É neste tempo que a interpretação do analista se orienta, cujas pistas são fornecidas pela transferência. Interrogamo-nos: é possível aproximar a noção de tempo pulsional do conceito de tempo em Tarkovski?

Privado de memória, o homem vive à margem do tempo. Ele se interroga sobre o que é o passado e afirma que o passado é portador de tudo o que é constante na realidade do presente, de cada momento do presente (TARKOVSKI, 2010). Tema já estudado por Freud, que revela que, quanto maior a resistência, mais a recordação se dá como repetição, esta compreendida enquanto atualização. A repetição é diferente do lembrar, pois repetir é atuar de acordo com as condições que as resistências impõem à fala do analisando. Na transferência, a neurose ordinária do paciente é substituída por uma neurose de transferência que viabilizará o trabalho 
analítico, pois a neurose de transferência possui caráter artificial, mas assume os sintomas e características patológicas da neurose (FREUD, 1914/2010). Tarkovski nos diz que o passado parece ser mais estável e mais real que o presente que se desliza e se esvai por entre os dedos, se tornando denso e material somente através da recordação. E o cinema é "a possibilidade de imprimir em celulóide a realidade do tempo" (TARKOVSKI, 2010, p.71)

O diretor afirma, ainda, que é necessário se apropriar do tempo, material inteiramente novo e que caracteriza o cinema como uma arte particular, uma nova musa. $\mathrm{O}$ cinema surge como novo princípio estético e não deve ser reduzido a princípios característicos de outras artes, como a literatura ou a pintura (TARKOVSKI, 2010). Portanto, nesta articulação é importante destacar uma diferença radical entre os mecanismos inconscientes presentes na associação livre e a apreensão de Tarkovski do material fílmico: o cinema é um tipo de linguagem radicalmente distante da linguagem verbal. O cinema comporta uma face de comunicação outra, que se dá através de sentimentos e imagens. "Uma combinação de conceitos literários e formas pictóricas jamais poderá ser uma imagem cinematográfica: tal combinação só poderá resultar numa forma híbrida mais ou menos vazia e presunçosa.” (TARKOVSKI, 2010, p. 73).

Assim como na conhecida analogia de Freud, que indica que o trabalho do analista está mais próximo do trabalho do escultor de retirar excessos, reconhecendo a produção de saber do analisando sobre sua verdade, Tarkovski entende o trabalho do cineasta como o trabalho sobre um 'bloco de tempo', do qual corta e rejeita aquilo que não necessita, deixando o que se mostra como elemento essencial da imagem cinematográfica.

O tempo é intrínseco às tomadas filmadas, é o que constituirá a lógica futura dos encadeamentos do filme, é o que vai definir como o filme deverá ser montado e indicar que montá-lo com competência significa respeitar o tempo impresso em cada tomada e deixá-las se juntarem espontaneamente. O papel do diretor, nesse sentido, é de reconhecer a singularidade de cada tomada e, a partir de então, realizar o trabalho da montagem. Esse tempo, como uma espécie de vestígio que se repete nas tomadas e demanda um olhar atento do diretor para realizar a montagem, pode se relacionar com o modo como o analista opera durante a análise.

Tarkovski ressalta que "o artista tem o dever de ser imperturbável. Não tem nenhum direito de revelar suas emoções, seu envolvimento, ou de jogar isso tudo sobre o seu público. Qualquer tratamento mais arrebatado de um tema deve ser sublimado numa forma de severidade olímpica." (TARKOVSKI, 2010, p.90-91). Para ele, essa postura é um compromisso ético do artista com a sua própria verdade, pois esta o ajuda a construir sua própria concepção e segui- 
la até o fim, sem hesitar diante de críticas e atitudes hostis, mesmo que isto lhe custe o prazer de trabalhar.

\section{CONCLUSÃO}

Acreditamos que, com a experiência de Tarkovski no cinema, podemos aprender sobre a Psicanálise, na medida em que encontramos uma aproximação do conceito de tempo em Tarkovski na construção do filme, com o conceito de Associação Livre, que também é determinado por mecanismos próprios da lógica inconsciente, que não podem ser alterados, mas requerem um manejo preciso e cuidadoso por parte do analista, como, por exemplo, a operação de interpretação.

Outro ponto de aproximação é a ideia que Tarkovski tem do conceito de verdade no cinema, que situa como uma forma que é instituída pela experiência singular e única, primeiro pelo artista, depois pelo espectador, de modo que esta verdade jamais remete a um simbolismo, nem se reduz a um conteúdo. Essa aproximação entre a interpretação e a construção do filme contribui para apreensão do tratamento que a Psicanálise confere ao tempo e à memória e, de igual modo, abre chaves de leitura importantes no debate sobre o tempo no âmbito do Cinema.

\section{REFERÊNCIAS}

BARBOSA, Pablo Bergami Goulart. Um olhar impossível: Construção psicanalítica e montagem cinematográfica. 2006. 89 f. Dissertação (Mestrado) - Curso de Psicologia, Universidade de Brasília, Brasília, 2006. Disponível em:

<http://repositorio.unb.br/bitstream/10482/6493/1/2006_Pablo\%20Bergami\%20Goulart\%20B arbosa.pdf>. Acesso em: 23 ago. 2018.

FONTENELE, Laéria Bezerra. A interpretação. 1. ed. Rio de Janeiro: Jorge Zahar Ed., 2002. FREUD, Sigmund. (1937) Construções em Análise. In: FREUD, Sigmund. Moisés e o Monoteísmo, Esboço de Psicanálise e outros trabalhos. 1. ed. Rio de Janeiro: Imago, 1996.

FREUD, Sigmund. (1899) Lembranças Encobridoras. In: FREUD, Sigmund. Primeiras Publicações Psicanalíticas. 1. ed. Rio de Janeiro: Imago, 1996. 
FREUD, Sigmund. (1925) Nota sobre o "Bloco Mágico". In: FREUD, Sigmund. O Eu e o Id, "autobiografia" e outros textos. 1. ed. São Paulo: Companhia das Letras, 2011.

FREUD, Sigmund. (1913) O Início do Tratamento. In: FREUD, Sigmund. Observações psicanalíticas sobre um caso de paranoia relatado em autobiografia: (O caso Schreber), artigos sobre técnica e outros textos. 1. ed. São Paulo: Companhia das Letras, 2010.

FREUD, Sigmund. (1914) Repetir, Recordar, Elaborar. In: FREUD, Sigmund. Observações psicanalíticas sobre um caso de paranoia relatado em autobiografia: (O caso Schreber), artigos sobre técnica e outros textos. 1. ed. São Paulo: Companhia das Letras, 2010.

FREUD, Sigmund. (1905[1904]) Sobre a Psicoterapia. In: FREUD, Sigmund. Um Caso de Histeria, Três Ensaios Sobre a Sexualidade e outros trabalhos. 1. ed. Rio de Janeiro: Imago, 1996.

FROEMMING, Liliane Seide. A montagem no Cinema e a associação livre na Psicanálise. 2002. Tese (Doutorado em Psicologia) — Instituto de Psicologia, Universidade Federal do Rio Grande do Sul, Porto Alegre, 2002.

JORGE, Marco Antonio Coutinho. Fundamentos da psicanálise de Freud a Lacan, vol. 1: as bases conceituais. 1. ed. Rio de Janeiro: Jorge Zahar Ed., 2000.

JORGE, Marco Antonio Coutinho. Fundamentos da psicanálise de Freud a Lacan, vol. 3: a prática analítica. 1. ed. Rio de Janeiro: Zahar, 2017.

RIVERA, Tania. Cinema, Imagem e Psicanálise. 1. ed. Rio de Janeiro: Jorge Zahar Ed., 2008 .

TARKOVSKI, Andrei. Esculpir o tempo. 3. ed. São Paulo: Martins Fontes, 2010. 